\title{
Development and radiolabeling of lipid nanoparticles with [99mTc]Tc-HMPAO: Characterization, stability, cytotoxicity and cell binding studies
}

\author{
Evren ATLIHAN-GÜNDOĞDU 1 (D), Meliha EKİNCİ 1,* (D), Emre ÖZGENÇ 1 (D), Emine Selin DEMİR1 ${ }^{\mathbb{D}}$, \\ Derya İLEM-ÖZDEMIR ${ }^{1}$ (D)
}

1 Department of Radiopharmacy, Faculty of Pharmacy, Ege University, Bornova 35100 Izmir, Turkey.

* Corresponding Author. E-mail: melihaekinci90@gmail.com (M.E.); Tel. +90-232-311 3282.

Received: 21 May 2021 / Revised: 20 September 2021 / Accepted: 15 November 2021

\begin{abstract}
In this study, we aimed to develop new lipid based nanoparticles (LPNs) and radiolabeled LPNs with [99mTc]Tc-HMPAO to investigate its cell binding capacity comparatively with [99mTc]Tc-HMPAO on different cancer cells. According to obtained results, LPNs with zeta potential of $-27.4 \pm 0.95 \mathrm{mV}$, particle size of $93.5 \pm 1.17 \mathrm{~nm}$, and polydispersity index of $0.35 \pm 0.04$ were successfully developed. The optimum radiolabeling efficiency was found to be

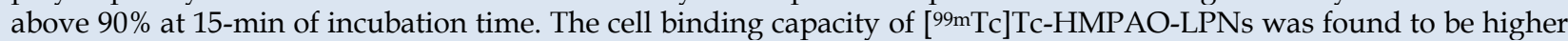
than $\left[{ }^{99 \mathrm{mTc}}\right] \mathrm{Tc}-\mathrm{HMPAO}$ in cancer cell lines. The results demonstrated that [99mTc]Tc-HMPAO-LPNs may be a promising

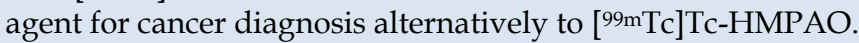

KEYWORDS: Lipid nanoparticles; radiopharmaceuticals; HMPAO; cell binding; cancer diagnosis.

\section{INTRODUCTION}

Nanotechnology is significant features for diagnosis and therapeutics [1-4]. The initial studies begin with development of the submicron emulsions in this area and continuous attempts have been provided by preparation of novel colloidal nanoparticles to improve the drug delivery [5-7]. Liposomes, micelles, nanoemulsions, nanosuspensions, solid lipid nanoparticles, and nanostructured lipid carriers are called lipidbased nanoparticles (LPNs). LPNs are generally formed of lipid, surfactant and water phases and have some advantages such as easy to prepare, biocompatible facility, low cost, good stability, long shelf-life, ease of storage. LPNs have a significant role in nuclear medicine application. LPNs preferentially accumulate in or around disease-target cells for the functional delivery of therapeutic agents for treatment or of imaging agents for diagnosis. LPNs are extensively assayed in in vitro cancer diagnosis and therapy [8].

In nuclear medicine, there are several diagnostic radionuclides. Among them, Technetium-99m ([99m $\mathrm{Tc}] \mathrm{Tc})$ is most preferred radionuclide due to the suitable properties such as $6 \mathrm{~h}$ half-life, low cost, easily availability from generator, and readily detectable gamma rays [9].

Because of nanoparticles as an ideal carrier in drug delivery, an easy method for radiolabeling of prepared LPN developed. In this context, it was reported a liposome labeling method for the lipophilic [99m Tc]hexamethyl propylene amine oxime ([99m Tc]Tc-HMPAO) complex [10]. They emphasized that [ ${ }^{99 \mathrm{mTc}] \mathrm{Tc}-}$ HMPAO obtains good radiochemical purity and stability for liposomes and seems to pass through the outer layer of the liposomes.

Due to the advantages of LPNs as drug delivery system, new LPNs were developed and prepared by using emulsion and sonication techniques. They were evaluated in terms of particle size, zeta potential, polydispersity index (PDI), stability, and cytotoxicity studies. In addition, [99mTc]Tc-HMPAO-LPNs were radiolabeled. The effects of the most valuable parameters on radiolabeling efficiency or radiochemical purity, including radiation dose and incubation time were studied. The in vitro stability of radiolabeled LPN was determined in saline and cell medium. Finally, cell binding studies for [ $\left.{ }^{99 \mathrm{~m} T c}\right] \mathrm{NaTcO}_{4}^{-},{ }^{99 \mathrm{~m} T c}$ ]Tc-HMPAO, [99mTc]Tc-HMPAO-LPN were comparatively investigated by using MCF-7 as human breast cancer cell line, PCS-440-010 as human prostate cancer cell line and CRL-10742 as human brain cancer cell line.

How to cite this article: Atlıhan-Gündoğdu E, Ekinci M, Özgenç E, Demir ES, Ilem-Özdemir D. Development and radiolabeling of lipid nanoparticles

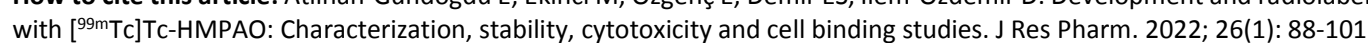




\section{RESULTS}

\subsection{Preparation of LPNs}

Preparation of LPN was accomplished to select convenient proportion of lipid, surfactant, solvents, stirring rate, stirring time and the sonication condition to evolve stable LPN. Many formulations having different ratio of vehicles have been assayed and showed in Table 1.

Table 1. Composition of LPNs.

\begin{tabular}{|c|c|c|c|}
\hline Formulations & $\begin{array}{c}\text { Lipid phase } \\
\text { Gelucire 48/16 pellets (mg) }\end{array}$ & $\begin{array}{l}\text { Surfactant phase } \\
\text { Span } 80(\mathrm{mg})\end{array}$ & $\begin{array}{c}\text { Liquid Phase } \\
\text { Distilled water }(\mathrm{mL}) \\
\end{array}$ \\
\hline F-1 & 200 & 200 & 10 \\
\hline F-2 & 200 & 150 & 10 \\
\hline F-3 & 200 & 50 & 10 \\
\hline F-4 & 100 & 300 & 10 \\
\hline F-5 & 100 & 200 & 10 \\
\hline Formulations & $\begin{array}{c}\text { Lipid phase } \\
\text { Gelucire } 48 / 16 \text { pellets }(\mathrm{mg})\end{array}$ & $\begin{array}{l}\text { Surfactant phase } \\
\text { Lipoid S } 75(\mathrm{mg})\end{array}$ & $\begin{array}{c}\text { Liquid phase } \\
\text { Distilled water: acetone: } \\
\text { ethanol }(3: 4: 3 \mathrm{v} / \mathrm{v})(\mathrm{mL})\end{array}$ \\
\hline F-6 & 300 & 300 & 10 \\
\hline F-7 & 300 & 200 & 10 \\
\hline F-8 & 200 & 300 & 10 \\
\hline F-9 & 200 & 200 & 10 \\
\hline F-10 & 100 & 300 & 10 \\
\hline F-11 & 100 & 200 & 10 \\
\hline F-12 & 100 & 100 & 10 \\
\hline F-13 & 100 & 50 & 10 \\
\hline Formulations & $\begin{array}{c}\text { Lipid phase } \\
\text { Gelucire } 48 / 16 \text { pellets }(\mathrm{mg})\end{array}$ & $\begin{array}{l}\text { Surfactant phase } \\
\text { Lipoid S } 100(\mathrm{mg})\end{array}$ & $\begin{array}{c}\text { Liquid phase } \\
\text { Distilled water: acetone: } \\
\text { ethanol }(3: 4: 3 \mathrm{v} / \mathrm{v})(\mathrm{mL})\end{array}$ \\
\hline F-14 & 300 & 300 & 10 \\
\hline F-15 & 200 & 300 & 10 \\
\hline F-16 & 200 & 200 & 10 \\
\hline F-17 & 200 & 100 & 10 \\
\hline F-18 & 100 & 300 & 10 \\
\hline F-19 & 100 & 200 & 10 \\
\hline F-20 & 100 & 100 & 10 \\
\hline
\end{tabular}

\subsection{Characterization of LPN}

\subsubsection{Particle size, zeta potential and polydispersity index}

The particle size, PDI and zeta potential of the developed LPN ranged from 45 to $309 \mathrm{~nm}, 0.13$ to 0.71 , 13 to $-42 \mathrm{mV}$, respectively (Table 2). Particle size and zeta potential play an important role in the interaction of formulation with biological system. The usage of high surfactant concentration in the preparation process leads to high zeta potential value and surface area and also reduction in particle size. The PDI value expresses whether the formulations prepared have homogeneous particle distributions. If the formulation has high PDI value, there are differently size particles in the system [11-14].

Herein, while some of formulations have below 0.5 of PDI, the others do not meet this requirement. Also, some of them were excluded because of their particle size that is above $100 \mathrm{~nm}$. According to results, formulation $7,8,10,11,14,17,18,19,20$ were used for further studies.

\subsection{Stability study}

Stability study is necessary to approve that the physicochemical characteristics of formulations and they are maintained over time, since degradation of LPN could influence their potential as effective drug delivery system. The appearance of the formulations did not change during the stability study. Furthermore, no 
statistically significant difference was observed in their particle sizes, zeta potentials and PDIs during 6 months for each storage conditions. On the other hand, the particle size values were found to be in accordance with desired values for LPNs (below $100 \mathrm{~nm}$ ) (Table 3-5). PDI values exceeded 0.5 for F-18 (Table 3-5) and other formulations presented a homogenous distribution during the storage period. In addition, zeta potential results demonstrated that statistically significant differences between the formulations were not observed (Table 3-5) under storage conditions and periods. As a result, the optimal formulations were chosen according to particle size, zeta potential, PDI and they ensured physicochemical stability for up to 6 months except F-18.

Table 2. The particle size, zeta potential and PDI of LPNs at the beginning (Mean $\pm S D, n=3$ ).

\begin{tabular}{lccc}
\hline Formulations & Particle size $(\mathbf{n m} \pm$ SD) & PDI & Zeta potential (mV \pm SD) \\
\hline F-1 & $177.4 \pm 11.38$ & $0.52 \pm 0.11$ & $-42.1 \pm 2.05$ \\
F-2 & $234.6 \pm 15.98$ & $0.38 \pm 0.05$ & $-40.2 \pm 2.25$ \\
F-3 & $172.8 \pm 9.35$ & $0.40 \pm 0.09$ & $-36.1 \pm 0.41$ \\
F-4 & $196.2 \pm 6.87$ & $0.42 \pm 0.09$ & $-33.9 \pm 1.10$ \\
F-5 & $175.2 \pm 2.50$ & $0.41 \pm 0.11$ & $-25.7 \pm 1.18$ \\
F-6 & $165.9 \pm 72.44$ & $0.70 \pm 0.34$ & $-18.0 \pm 1.44$ \\
F-7 & $45.08 \pm 0.61$ & $0.29 \pm 0.04$ & $-17.3 \pm 2.84$ \\
F-8 & $49.91 \pm 13.56$ & $0.49 \pm 0.08$ & $-27.8 \pm 2.28$ \\
F-9 & $165.9 \pm 72.44$ & $0.61 \pm 0.32$ & $-18.0 \pm 1.44$ \\
F-10 & $75.08 \pm 0.61$ & $0.29 \pm 0.04$ & $-17.3 \pm 2.84$ \\
F-11 & $89.91 \pm 13.56$ & $0.49 \pm 0.08$ & $-27.8 \pm 2.28$ \\
F-12 & $157.1 \pm 4.22$ & $0.14 \pm 0.07$ & $-30.3 \pm 10.2$ \\
F-13 & $309.3 \pm 10.86$ & $0.30 \pm 0.03$ & $-13.5 \pm 0.20$ \\
F-14 & $97.40 \pm 1.17$ & $0.35 \pm 0.04$ & $-17.4 \pm 0.95$ \\
F-15 & $157.1 \pm 4.223$ & $0.14 \pm 0.03$ & $-30.3 \pm 10.2$ \\
F-16 & $309.3 \pm 10.86$ & $0.30 \pm 0.03$ & $-13.5 \pm 0.20$ \\
F-17 & $93.5 \pm 1.166$ & $0.35 \pm 0.04$ & $-27.4 \pm 0.95$ \\
F-18 & $102.3 \pm 0.64$ & $0.52 \pm 0.02$ & $-23.9 \pm 4.21$ \\
F-19 & $79.76 \pm 1.28$ & $0.44 \pm 0.02$ & $-29.6 \pm 1.47$ \\
F-20 & $68.97 \pm 1.11$ & $0.38 \pm 0.07$ & $-20.8 \pm 0.73$ \\
\hline & & &
\end{tabular}

Table 3. The particle size, zeta potential and PDI of LPNs at $5 \pm 3^{\circ} \mathrm{C}(\mathrm{Mean} \pm S D, n=3)$.

\begin{tabular}{|c|c|c|c|c|c|c|c|c|c|}
\hline & \multicolumn{3}{|c|}{ Beginning } & \multicolumn{3}{|c|}{3 months } & \multicolumn{3}{|c|}{6 months } \\
\hline For. & $\begin{array}{c}\text { Particle } \\
\text { size } \\
(\mathrm{nm} \pm \mathrm{SD})\end{array}$ & PDI & $\begin{array}{c}\text { Zeta } \\
\text { Potential } \\
(\mathrm{mV} \pm \mathrm{SD})\end{array}$ & $\begin{array}{c}\text { Particle size } \\
\text { (nm } \pm \text { SD) }\end{array}$ & PDI & $\begin{array}{c}\text { Zeta } \\
\text { Potential } \\
(\mathrm{mV} \pm S D)\end{array}$ & $\begin{array}{c}\text { Particle } \\
\text { size } \\
(\mathrm{nm} \pm \mathrm{SD})\end{array}$ & PDI & $\begin{array}{c}\text { Zeta } \\
\text { Potential } \\
(\mathrm{mV} \pm S D)\end{array}$ \\
\hline F-7 & $\begin{array}{c}45.08 \pm \\
0.61\end{array}$ & $\begin{array}{c}0.29 \pm \\
0.04\end{array}$ & $\begin{array}{c}-17.3 \pm \\
2.84\end{array}$ & $\begin{array}{c}41.17 \pm \\
13.67\end{array}$ & $\begin{array}{c}0.25 \pm \\
0.18\end{array}$ & $\begin{array}{c}-18.08 \pm \\
4.02\end{array}$ & $\begin{array}{c}46.07 \pm \\
5.21\end{array}$ & $\begin{array}{c}0.37 \pm \\
0.04\end{array}$ & $\begin{array}{c}-25.88 \pm \\
4.72\end{array}$ \\
\hline F-8 & $\begin{array}{c}49.91 \pm \\
13.56\end{array}$ & $\begin{array}{c}0.49 \pm \\
0.08\end{array}$ & $\begin{array}{c}-27.8 \pm \\
2.28\end{array}$ & $\begin{array}{c}48.23 \pm \\
9.80\end{array}$ & $\begin{array}{c}0.37 \pm \\
0.12\end{array}$ & $\begin{array}{c}-26.88 \pm \\
5.80\end{array}$ & $\begin{array}{c}53.23 \pm \\
15.90\end{array}$ & $\begin{array}{c}0.25 \pm \\
0.17\end{array}$ & $\begin{array}{c}-27.00 \pm \\
3.61\end{array}$ \\
\hline F-10 & $\begin{array}{c}75.08 \pm \\
0.61\end{array}$ & $\begin{array}{c}0.29 \pm \\
0.04\end{array}$ & $\begin{array}{c}-17.3 \pm \\
2.84\end{array}$ & $\begin{array}{c}77.78 \pm \\
14.53\end{array}$ & $\begin{array}{c}0.28 \pm \\
0.06\end{array}$ & $\begin{array}{c}-16.45 \pm \\
3.16\end{array}$ & $\begin{array}{c}80.56 \pm \\
4.84\end{array}$ & $\begin{array}{c}0.34 \pm \\
0.29\end{array}$ & $\begin{array}{c}-30.31 \pm \\
2.86\end{array}$ \\
\hline F-11 & $\begin{array}{c}89.91 \pm \\
13.56\end{array}$ & $\begin{array}{c}0.49 \pm \\
0.08\end{array}$ & $\begin{array}{c}-27.8 \pm \\
2.28\end{array}$ & $\begin{array}{c}81.34 \pm \\
29.80\end{array}$ & $\begin{array}{c}0.38 \pm \\
0.17\end{array}$ & $\begin{array}{c}-26.73 \pm \\
5.51\end{array}$ & $\begin{array}{c}89.89 \pm \\
18.13\end{array}$ & $\begin{array}{c}0.37 \pm \\
0.14\end{array}$ & $\begin{array}{c}-30.56 \pm \\
1.72\end{array}$ \\
\hline F-14 & $\begin{array}{c}97.40 \pm \\
1.17\end{array}$ & $\begin{array}{c}0.35 \pm \\
0.04\end{array}$ & $\begin{array}{c}-17.4 \pm \\
0.95\end{array}$ & $\begin{array}{c}87.63 \pm \\
3.67\end{array}$ & $\begin{array}{c}0.29 \pm \\
0.13\end{array}$ & $\begin{array}{c}-19.12 \pm \\
3.19\end{array}$ & $\begin{array}{c}96.22 \pm \\
5.37\end{array}$ & $\begin{array}{c}0.26 \pm \\
0.29\end{array}$ & $\begin{array}{c}-28.29 \pm \\
2.64\end{array}$ \\
\hline F-17 & $\begin{array}{c}93.5 \pm \\
1.17\end{array}$ & $\begin{array}{c}0.35 \pm \\
0.04\end{array}$ & $\begin{array}{c}-27.4 \pm \\
0.95\end{array}$ & $\begin{array}{c}96.66 \pm \\
7.79\end{array}$ & $\begin{array}{c}0.37 \pm \\
0.19\end{array}$ & $\begin{array}{c}-26.75 \pm \\
3.28\end{array}$ & $\begin{array}{c}96.71 \pm \\
5.61\end{array}$ & $\begin{array}{c}0.32 \pm \\
0.06\end{array}$ & $\begin{array}{c}-27.45 \pm \\
1.46\end{array}$ \\
\hline F-18 & $\begin{array}{c}102.3 \pm \\
0.64\end{array}$ & $\begin{array}{c}0.52 \pm \\
0.02\end{array}$ & $\begin{array}{c}-23.9 \pm \\
4.21\end{array}$ & $\begin{array}{c}189.01 \pm \\
1.17\end{array}$ & $\begin{array}{c}0.78 \pm \\
0.19\end{array}$ & $\begin{array}{c}-25.88 \pm \\
2.37\end{array}$ & $\begin{array}{c}159.41 \pm \\
6.1\end{array}$ & $\begin{array}{c}0.25 \pm \\
0.28\end{array}$ & $\begin{array}{c}-27.45 \pm \\
1.25\end{array}$ \\
\hline F-19 & $\begin{array}{c}79.76 \pm \\
1.28\end{array}$ & $\begin{array}{c}0.44 \pm \\
0.02\end{array}$ & $\begin{array}{c}-29.6 \pm \\
1.47\end{array}$ & $\begin{array}{c}86.95 \\
\pm 11.79\end{array}$ & $\begin{array}{c}0.33 \pm \\
0.21\end{array}$ & $\begin{array}{c}-28.67 \pm \\
4.08\end{array}$ & $\begin{array}{c}93.52 \pm \\
15.33\end{array}$ & $\begin{array}{c}0.23 \pm \\
0.1\end{array}$ & $\begin{array}{c}-28.48 \pm \\
2.36\end{array}$ \\
\hline F-20 & $\begin{array}{c}68.97 \pm \\
1.11\end{array}$ & $\begin{array}{c}0.38 \pm \\
0.07\end{array}$ & $\begin{array}{c}-20.8 \pm \\
0.73\end{array}$ & $\begin{array}{c}70.08 \pm \\
13.65\end{array}$ & $\begin{array}{c}0.28 \pm \\
0.16\end{array}$ & $\begin{array}{c}-21.93 \pm \\
4.24\end{array}$ & $\begin{array}{c}75.67 \pm \\
15\end{array}$ & $\begin{array}{c}0.25 \pm \\
0.17\end{array}$ & $\begin{array}{c}-30.07 \pm \\
2.05\end{array}$ \\
\hline
\end{tabular}


Table 4. The particle size, zeta potential and PDI of LPNs at $25 \pm 5^{\circ} \mathrm{C}, 60 \pm 5 \%$ relative humidity (Mean $\pm S D, n=3$ ).

\begin{tabular}{|c|c|c|c|c|c|c|c|c|c|}
\hline \multirow[b]{2}{*}{ For. } & \multicolumn{3}{|c|}{ Beginning } & \multicolumn{3}{|c|}{3 months } & \multicolumn{3}{|c|}{6 months } \\
\hline & $\begin{array}{l}\text { Particle } \\
\text { size } \\
(\mathrm{nm} \pm \mathrm{SD})\end{array}$ & PDI & $\begin{array}{c}\text { Zeta } \\
\text { Potential } \\
(\mathrm{mV \pm SD)}\end{array}$ & $\begin{array}{l}\text { Particle } \\
\text { size } \\
(\mathrm{nm} \pm \mathrm{SD})\end{array}$ & PDI & $\begin{array}{c}\text { Zeta } \\
\text { Potential } \\
(\mathrm{mV} \pm S D)\end{array}$ & $\begin{array}{l}\text { Particle } \\
\text { size } \\
(\mathrm{nm} \pm \mathrm{SD})\end{array}$ & PDI & $\begin{array}{c}\text { Zeta } \\
\text { Potential } \\
(\mathrm{mV} \pm S D)\end{array}$ \\
\hline F-7 & $\begin{array}{c}45.08 \pm \\
0.61\end{array}$ & $\begin{array}{c}0.29 \pm \\
0.04\end{array}$ & $\begin{array}{c}-17.3 \pm \\
2.84\end{array}$ & $\begin{array}{c}47.59 \pm \\
1.33\end{array}$ & $\begin{array}{c}0.36 \pm \\
0.21\end{array}$ & $\begin{array}{c}-21.41 \pm \\
1.80\end{array}$ & $\begin{array}{c}83.04 \pm \\
5.18\end{array}$ & $\begin{array}{c}0.37 \pm \\
0.23\end{array}$ & $\begin{array}{c}-28.48 \pm \\
2.55\end{array}$ \\
\hline F-8 & $\begin{array}{c}49.91 \pm \\
13.56\end{array}$ & $\begin{array}{c}0.49 \pm \\
0.08\end{array}$ & $\begin{array}{c}-27.8 \pm \\
2.28\end{array}$ & $\begin{array}{c}50.79 \pm \\
2.4\end{array}$ & $\begin{array}{c}0.38 \pm \\
0.22\end{array}$ & $\begin{array}{c}-29.34 \pm \\
2.45\end{array}$ & $\begin{array}{c}54.79 \pm \\
5.04\end{array}$ & $\begin{array}{c}0.38 \pm \\
0.20\end{array}$ & $\begin{array}{c}-29.23 \pm \\
1.18\end{array}$ \\
\hline F-10 & $\begin{array}{c}75.08 \pm \\
0.61\end{array}$ & $\begin{array}{c}0.29 \pm \\
0.04\end{array}$ & $\begin{array}{c}-17.3 \pm \\
2.84\end{array}$ & $\begin{array}{c}82.86 \pm \\
2.14\end{array}$ & $\begin{array}{c}0.28 \pm \\
0.07\end{array}$ & $\begin{array}{c}-28.02 \pm \\
1.56\end{array}$ & $\begin{array}{c}73.14 \pm \\
6.55\end{array}$ & $\begin{array}{c}0.33 \pm \\
0.31\end{array}$ & $\begin{array}{c}-27.92 \pm \\
3.96\end{array}$ \\
\hline F-11 & $\begin{array}{c}89.91 \pm \\
13.56\end{array}$ & $\begin{array}{c}0.49 \pm \\
0.08\end{array}$ & $\begin{array}{c}-27.8 \pm \\
2.28\end{array}$ & $\begin{array}{c}86.83 \pm \\
0.63\end{array}$ & $\begin{array}{c}0.34 \pm \\
0.11\end{array}$ & $\begin{array}{c}-29.81 \pm \\
0.63\end{array}$ & $\begin{array}{c}82.59 \pm \\
10.95\end{array}$ & $\begin{array}{c}0.41 \pm \\
0.23\end{array}$ & $\begin{array}{c}-31.15 \pm \\
1.79\end{array}$ \\
\hline F-14 & $\begin{array}{c}97.40 \pm \\
1.17\end{array}$ & $\begin{array}{c}0.35 \pm \\
0.04\end{array}$ & $\begin{array}{c}-17.4 \pm \\
0.95\end{array}$ & $\begin{array}{c}94.93 \pm \\
1.70\end{array}$ & $\begin{array}{l}0.3 \pm \\
0.12\end{array}$ & $\begin{array}{c}-29.12 \pm \\
3.19\end{array}$ & $\begin{array}{c}107.23 \pm \\
13.81\end{array}$ & $\begin{array}{c}0.37 \pm \\
0.15\end{array}$ & $\begin{array}{c}-29.44 \pm \\
0.68\end{array}$ \\
\hline F-17 & $\begin{array}{c}93.5 \pm \\
1.17\end{array}$ & $\begin{array}{c}0.35 \pm \\
0.04\end{array}$ & $\begin{array}{c}-27.4 \pm \\
0.95\end{array}$ & $\begin{array}{c}94.22 \pm \\
3.99\end{array}$ & $\begin{array}{c}0.37 \pm \\
0.20\end{array}$ & $\begin{array}{c}-29.89 \pm \\
4.0\end{array}$ & $\begin{array}{c}96.60 \pm \\
5.29\end{array}$ & $\begin{array}{c}0.32 \pm \\
0.14\end{array}$ & $\begin{array}{c}-27.94 \pm \\
3.76\end{array}$ \\
\hline F-18 & $\begin{array}{c}102.3 \pm \\
0.64\end{array}$ & $\begin{array}{c}0.52 \pm \\
0.02\end{array}$ & $\begin{array}{c}-23.9 \pm \\
4.21\end{array}$ & $\begin{array}{c}184.04 \pm \\
3.48\end{array}$ & $\begin{array}{c}0.36 \pm \\
0.11\end{array}$ & $\begin{array}{c}-27.89 \pm \\
4.08\end{array}$ & $\begin{array}{c}177.7 \pm \\
4.0\end{array}$ & $\begin{array}{c}0.38 \pm \\
0.27\end{array}$ & $\begin{array}{c}-28.52 \pm \\
2.14\end{array}$ \\
\hline F-19 & $\begin{array}{c}79.76 \pm \\
1.28\end{array}$ & $\begin{array}{c}0.44 \pm \\
0.02\end{array}$ & $\begin{array}{c}-29.6 \pm \\
1.47\end{array}$ & $\begin{array}{c}75.86 \pm \\
2.2\end{array}$ & $\begin{array}{c}0.21 \pm \\
0.05\end{array}$ & $\begin{array}{c}-30.38 \pm \\
2.72\end{array}$ & $\begin{array}{c}73.01 \pm \\
6.21\end{array}$ & $\begin{array}{c}0.41 \pm \\
0.43\end{array}$ & $\begin{array}{c}-31.21 \pm \\
2.94\end{array}$ \\
\hline F-20 & $\begin{array}{c}68.97 \pm \\
1.11\end{array}$ & $\begin{array}{c}0.38 \pm \\
0.07\end{array}$ & $\begin{array}{c}-20.8 \pm \\
0.73\end{array}$ & $\begin{array}{c}61.12 \pm \\
9.61\end{array}$ & $\begin{array}{c}0.34 \pm \\
0.08\end{array}$ & $\begin{array}{c}-31.93 \pm \\
4.25\end{array}$ & $\begin{array}{c}60.26 \pm \\
8.63\end{array}$ & $\begin{array}{c}0.33 \pm \\
0.20\end{array}$ & $\begin{array}{c}-27.41 \pm \\
3.46\end{array}$ \\
\hline
\end{tabular}

Table 5. The particle size, zeta potential and PDI of LPNs $40 \pm 5^{\circ} \mathrm{C}, 75 \pm 5 \%$ relative humidity (Mean $\pm S D, n=3$ ).

\begin{tabular}{|c|c|c|c|c|c|c|c|c|c|}
\hline \multirow[b]{2}{*}{ For. } & \multicolumn{3}{|c|}{ Beginning } & \multicolumn{3}{|c|}{3 months } & \multicolumn{3}{|c|}{6 months } \\
\hline & $\begin{array}{l}\text { Particle } \\
\text { size } \\
(\mathrm{nm} \pm \mathrm{SD})\end{array}$ & PDI & $\begin{array}{c}\text { Zeta } \\
\text { Potential } \\
(\mathrm{mV} \pm S D)\end{array}$ & $\begin{array}{c}\text { Particle } \\
\text { size } \\
\text { (nm } \pm \text { SD) }\end{array}$ & PDI & $\begin{array}{c}\text { Zeta } \\
\text { Potential } \\
(\mathrm{mV} \pm S D)\end{array}$ & $\begin{array}{l}\text { Particle } \\
\text { size } \\
(\mathrm{nm} \pm \mathrm{SD})\end{array}$ & PDI & $\begin{array}{c}\text { Zeta } \\
\text { Potential } \\
(\mathrm{mV} \pm S D)\end{array}$ \\
\hline F-7 & $\begin{array}{c}45.08 \pm \\
0.61\end{array}$ & $\begin{array}{c}0.29 \pm \\
0.04\end{array}$ & $\begin{array}{c}-17.3 \pm \\
2.84\end{array}$ & $\begin{array}{c}46.46 \pm \\
5.52\end{array}$ & $\begin{array}{c}0.47 \pm \\
0.11\end{array}$ & $\begin{array}{c}-31.58 \pm \\
1.51\end{array}$ & $\begin{array}{c}53.13 \pm \\
5.92\end{array}$ & $\begin{array}{c}0.22 \pm \\
0.15\end{array}$ & $\begin{array}{c}-28.04 \pm \\
3.81\end{array}$ \\
\hline F-8 & $\begin{array}{c}49.91 \pm \\
13.56\end{array}$ & $\begin{array}{c}0.49 \pm \\
0.08\end{array}$ & $\begin{array}{c}-27.8 \pm \\
2.28\end{array}$ & $\begin{array}{c}56.45 \pm \\
5.64\end{array}$ & $\begin{array}{c}0.47 \pm \\
0.08\end{array}$ & $\begin{array}{c}-30.62 \pm \\
0.61\end{array}$ & $\begin{array}{c}54.97 \pm \\
3.90\end{array}$ & $\begin{array}{c}0.35 \pm \\
0.22\end{array}$ & $\begin{array}{c}-23.78 \pm \\
5.4\end{array}$ \\
\hline F-10 & $\begin{array}{c}75.08 \pm \\
0.61\end{array}$ & $\begin{array}{c}0.29 \pm \\
0.04\end{array}$ & $\begin{array}{c}-17.3 \pm \\
2.84\end{array}$ & $\begin{array}{c}88.82 \pm \\
8.68\end{array}$ & $\begin{array}{c}0.27 \pm \\
0.07\end{array}$ & $\begin{array}{c}-29.15 \pm \\
1.37\end{array}$ & $\begin{array}{c}94.82 \pm \\
4.77\end{array}$ & $\begin{array}{c}0.37 \pm \\
0.26\end{array}$ & $\begin{array}{c}-25.52 \pm \\
5.43\end{array}$ \\
\hline F-11 & $\begin{array}{c}89.91 \pm \\
13.56\end{array}$ & $\begin{array}{c}0.49 \pm \\
0.08\end{array}$ & $\begin{array}{c}-27.8 \pm \\
2.28\end{array}$ & $\begin{array}{c}100.24 \pm \\
10.43\end{array}$ & $\begin{array}{c}0.19 \pm \\
0.04\end{array}$ & $\begin{array}{c}-29.07 \pm \\
1.17\end{array}$ & $\begin{array}{c}104.52 \pm \\
17.62\end{array}$ & $\begin{array}{c}0.25 \pm \\
0.10\end{array}$ & $\begin{array}{c}-28.98 \pm \\
2.01\end{array}$ \\
\hline F-14 & $\begin{array}{c}97.40 \pm \\
1.17\end{array}$ & $\begin{array}{c}0.35 \pm \\
0.04\end{array}$ & $\begin{array}{c}-17.4 \pm \\
0.95\end{array}$ & $\begin{array}{c}94.71 \pm \\
12.82\end{array}$ & $\begin{array}{c}0.26 \pm \\
0.18\end{array}$ & $\begin{array}{c}-28.64 \pm \\
4.04\end{array}$ & $\begin{array}{c}100.82 \pm \\
11.92\end{array}$ & $\begin{array}{c}0.37 \pm \\
0.15\end{array}$ & $\begin{array}{c}-25.19 \pm \\
5.28\end{array}$ \\
\hline F-17 & $93.5 \pm 1.17$ & $\begin{array}{c}0.35 \pm \\
0.04\end{array}$ & $\begin{array}{c}-27.4 \pm \\
0.95\end{array}$ & $\begin{array}{c}99.97 \pm \\
9.77\end{array}$ & $\begin{array}{c}0.35 \pm \\
0.07\end{array}$ & $\begin{array}{c}-28.59 \pm \\
2.64\end{array}$ & $\begin{array}{c}92.59 \pm \\
26.04\end{array}$ & $\begin{array}{c}0.29 \pm \\
0.18\end{array}$ & $\begin{array}{c}-28.16 \pm \\
7.75\end{array}$ \\
\hline F-18 & $\begin{array}{c}102.3 \pm \\
0.64\end{array}$ & $\begin{array}{c}0.52 \pm \\
0.02\end{array}$ & $\begin{array}{c}-23.9 \pm \\
4.21\end{array}$ & $\begin{array}{c}185.02 \pm \\
4.84\end{array}$ & $\begin{array}{c}0.35 \pm \\
0.1\end{array}$ & $\begin{array}{c}-24.63 \pm \\
4.91\end{array}$ & $\begin{array}{c}192.41 \pm \\
6.90\end{array}$ & $\begin{array}{c}0.20 \pm \\
0.12\end{array}$ & $\begin{array}{c}-25.56 \pm \\
2.22\end{array}$ \\
\hline F-19 & $\begin{array}{c}79.76 \pm \\
1.28\end{array}$ & $\begin{array}{c}0.44 \pm \\
0.02\end{array}$ & $\begin{array}{c}-29.6 \pm \\
1.47\end{array}$ & $\begin{array}{c}85.18 \pm \\
4.59\end{array}$ & $\begin{array}{c}0.21 \pm \\
0.05\end{array}$ & $\begin{array}{c}-29.05 \pm \\
3.71\end{array}$ & $\begin{array}{c}89.31 \pm \\
8.36\end{array}$ & $\begin{array}{c}0.46 \pm \\
0.38\end{array}$ & $\begin{array}{c}-26.28 \pm \\
4.58\end{array}$ \\
\hline F-20 & $\begin{array}{c}68.97 \pm \\
1.11\end{array}$ & $\begin{array}{c}0.38 \pm \\
0.07\end{array}$ & $\begin{array}{c}-20.8 \pm \\
0.73\end{array}$ & $\begin{array}{c}64.41 \pm \\
13.23\end{array}$ & $\begin{array}{c}0.38 \pm \\
0.14\end{array}$ & $\begin{array}{c}-28.85 \pm \\
2.06\end{array}$ & $\begin{array}{c}63.12 \pm \\
7.28\end{array}$ & $\begin{array}{c}0.58 \pm \\
0.08\end{array}$ & $\begin{array}{c}-27.04 \pm \\
3.29\end{array}$ \\
\hline
\end{tabular}

\subsection{Cell culture studies}

\subsubsection{Cell viability studies}

The number of micro aggregates cells (non-blue-stained cells) and blue-stained cells was counted by aid of hemocytometer. Table 6 shows the number of all cells and percentage of dead cells. The percentage of bluestained cells was found to be below 15\% for MCF-7, PCS-440-010 and CRL-10742 cell suspensions. These values are available for seeding in later studies [15].

\subsubsection{Cytotoxicity studies}

Eight formulations which have below $100 \mathrm{~nm}$ of particle size (Formulations 7, 8, 10, 11, 14, 17, 19, 20) were selected for cytotoxicity studies. While F-17 shows $95.55 \%, 95.12 \%, 94.34 \%$ cell viability for MCF-7, CRL10742, PCS-440-010 respectively, other formulations produce between $70.56 \%$ and $89.13 \%$ cell viability for all cells (Table 7). The IC 50 values of LPN formulations for MCF-7, CRL-10742, PCS-440-010 cells were found to 
be between $23.17 \pm 8.04$ and $9.15 \pm 2.04 \mu \mathrm{M}$ (Table 8 ). The highest cell viability ratios and $\mathrm{IC}_{50}$ values were obtained with formulation 17 and radiolabeling studies were performed F-17.

Table 6. The summary of cell counting results (Mean $\pm S D, n=3$ ).

\begin{tabular}{cccc}
\hline Cell types & \multicolumn{3}{c}{ Number of cells } \\
& MCF-7 & CRL-10742 & PCS-440-010 \\
\hline Non-blue-stained cells & $237.25 \pm 18.15$ & $230.75 \pm 1.71$ & $252.75 \pm 3.1$ \\
Blue-stained cells & $24.5 \pm 2.64$ & $25.25 \pm 1.70$ & $30.5 \pm 8.42$ \\
Dead cells \% & $9.38 \pm 0.25$ & $9.86 \pm 1.2$ & $10.77 \pm 0.82$ \\
\hline
\end{tabular}

Table 7. Cell viability ratios of $L P N$ formulations (Mean $\pm S D, n=3$ ).

\begin{tabular}{lcccccc}
\hline \multirow{2}{*}{ For. } & \multicolumn{2}{c}{ MCF-7 } & \multicolumn{2}{c}{ CRL-10742 } & \multicolumn{2}{c}{ PCS-440-010 } \\
\cline { 2 - 7 } & $\mathbf{2 4} \mathbf{h}$ & $\mathbf{4 8} \mathbf{h}$ & $\mathbf{2 4} \mathbf{~ h}$ & $\mathbf{4 8 ~ h}$ & $\mathbf{2 4} \mathbf{~ h}$ & $\mathbf{4 8} \mathbf{~}$ \\
\hline F-7 & $85.38 \pm 7.21$ & $84.78 \pm 6.99$ & $89.67 \pm 10.01$ & $89.03 \pm 11.23$ & $90.13 \pm 19.08$ & $89.13 \pm 7.89$ \\
F-8 & $72.49 \pm 9.56$ & $70.56 \pm 8.12$ & $74.90 \pm 7.78$ & $73.23 \pm 8.15$ & $78.15 \pm 1.16$ & $77.56 \pm 5.15$ \\
F-10 & $83.43 \pm 4.56$ & $84.13 \pm 9.09$ & $80.45 \pm 6.79$ & $76.17 \pm 12.09$ & $87.54 \pm 1.90$ & $80.18 \pm 7.14$ \\
F-11 & $85.24 \pm 12.23$ & $84.99 \pm 11.04$ & $80.56 \pm 6.78$ & $80.03 \pm 5.66$ & $87.34 \pm 11.56$ & $85.43 \pm 9.23$ \\
F-14 & $75.24 \pm 6.77$ & $74.78 \pm 10.65$ & $79.62 \pm 11.22$ & $79.03 \pm 10.56$ & $80.13 \pm 7.89$ & $79.13 \pm 7.33$ \\
F-17 & $96.45 \pm 8.15$ & $95.55 \pm 5.03$ & $97.12 \pm 6.78$ & $95.12 \pm 6.55$ & $95.13 \pm 2.34$ & $94.34 \pm 5.66$ \\
F-19 & $82.79 \pm 9.21$ & $80.46 \pm 8.55$ & $84.9 \pm 7.99$ & $83.23 \pm 8.56$ & $88.15 \pm 10.34$ & $87.56 \pm 5.67$ \\
F-20 & $90.35 \pm 8.78$ & $85.66 \pm 11.23$ & $87.12 \pm 6.66$ & $85.12 \pm 11.78$ & $85.45 \pm 17.36$ & $84.44 \pm 18.12$ \\
\hline
\end{tabular}

Table 8. $\mathrm{IC}_{50}$ values of LPN formulations (Mean $\pm \mathrm{SD}, \mathrm{n}=3$ ).

\begin{tabular}{cccc}
\hline \multirow{2}{*}{ For. } & \multicolumn{3}{c}{ IC $_{\mathbf{5 0}}(\boldsymbol{\mu M})$} \\
\cline { 2 - 4 } & MCF-7 & CRL-10742 & PCS-440-010 \\
\hline F-7 & $19.01 \pm 4.34$ & $19.34 \pm 2.98$ & $17.67 \pm 5.67$ \\
F-8 & $15.56 \pm 4.03$ & $16.64 \pm 7.78$ & $15.13 \pm 2.34$ \\
F-10 & $18.79 \pm 3.45$ & $18.77 \pm 4.09$ & $17.77 \pm 9.89$ \\
F-11 & $18.45 \pm 1.03$ & $18.14 \pm 6.77$ & $17.89 \pm 4.32$ \\
F-14 & $9.15 \pm 2.04$ & $9.64 \pm 1.07$ & $11.23 \pm 2.12$ \\
F-17 & $23.17 \pm 8.04$ & $22.93 \pm 9.87$ & $21.56 \pm 8.77$ \\
F-19 & $19.01 \pm 4.34$ & $19.34 \pm 2.98$ & $17.67 \pm 5.67$ \\
F-20 & $17.89 \pm 1.12$ & $19.78 \pm 4.67$ & $18.76 \pm 7.76$ \\
\hline
\end{tabular}

\subsection{Evaluation of radiochemical purity for $[99 \mathrm{mTc}] \mathrm{Tc}-\mathrm{HMPAO}$}

Preparation of [99m Tc]Tc-HMPAO was successfully performed. After that, quality control of [ ${ }^{99 \mathrm{~m} T c] \mathrm{Tc}-}$ HMPAO was determined by radioactive thin layer chromatography (RTLC). Instant Thin Layer Chromatography-Silica Gel coated fiber sheets (ITLC-SG) was used as stationary phase. Two solvents were used to distinguish and quantify the amounts of radioactive contaminants. The free [99mTc]Tc and [99mTc]TcHMPAO moved with the solvent front, while [99mTc]Tc-HMPAO and Reduced/Hydrolyzed (R/H) [99mTc]Tc remained at the spotting point in saline. $\mathrm{R} / \mathrm{H}\left[{ }^{99 \mathrm{~m}} \mathrm{Tc}\right] \mathrm{Tc}$ was determined by using methyl ethyl ketone (MEK) as the mobile phase where the $\mathrm{R} / \mathrm{H}{ }^{99 \mathrm{~m}} \mathrm{Tc}$ remained at the point of spotting while free [ ${ }^{99 \mathrm{~m} T c] \mathrm{Tc}}$ and [ ${ }^{99 \mathrm{~m} T c] \mathrm{Tc}}$ HMPAO moved with the solvent front. The Rf values of [99m Tc]Tc-HMPAO in mobile phases was presented in Table 9. According to results, the radiochemical purity of [99mTc]Tc-HMPAO was decreased to $80 \%$ after $2 \mathrm{~h}$ (Figure 1).

\subsection{Radiolabeling of LPN}

LPN (F-17) was incubated with 3.7 and $7.4 \mathrm{MBq}$ of [99mTc]Tc-HMPAO at various incubation times $(5,15$ and 30-min) to prepare [99m Tc]Tc-HMPAO-LPN. As shown in Figure 2 and Figure 3, the radiochemical purity value increased when the incubation time increased from 5 to $15 \mathrm{~min}$. The highest radiochemical purity $(\geq 90)$ was found after $15 \mathrm{~min}$. The incubation at $30 \mathrm{~min}$ resulted in a decrease in radiochemical purity value of radiolabeled LPN (below $85 \%$ ) after $4 \mathrm{~h}$ when compared with the incubation at $15 \mathrm{~min}$. Based on these results, the incubation time was selected as $15 \mathrm{~min}$ for radiolabeling procedure. 
Table 9. Rf values of [99mTc]Tc-HMPAO in mobile phases.

\begin{tabular}{|c|c|c|c|c|}
\hline & \multicolumn{2}{|c|}{ ITLC-SG paper } & \multicolumn{2}{|c|}{ ITLC-SG paper } \\
\hline & MEK* & Saline & $\begin{array}{l}\text { Pyridine/acetic } \\
\text { acid/water }\end{array}$ & Acetone \\
\hline Free $\left[{ }^{99 m T c}\right] \mathrm{Tc}$ & $0.8-1.0$ & $0.8-1.0$ & $0.8-1.0$ & $0.8-1.0$ \\
\hline $\mathrm{R} / \mathrm{H}\left[{ }^{99 \mathrm{~m}} \mathrm{Tc}\right] \mathrm{Tc}$ & $0.0-0.1$ & $0.0-0.1$ & $0.0-0.1$ & $0.0-0.1$ \\
\hline [99mTc]Tc-HMPAO & $0.0-0.2$ & $0.8-1.0$ & - & - \\
\hline
\end{tabular}

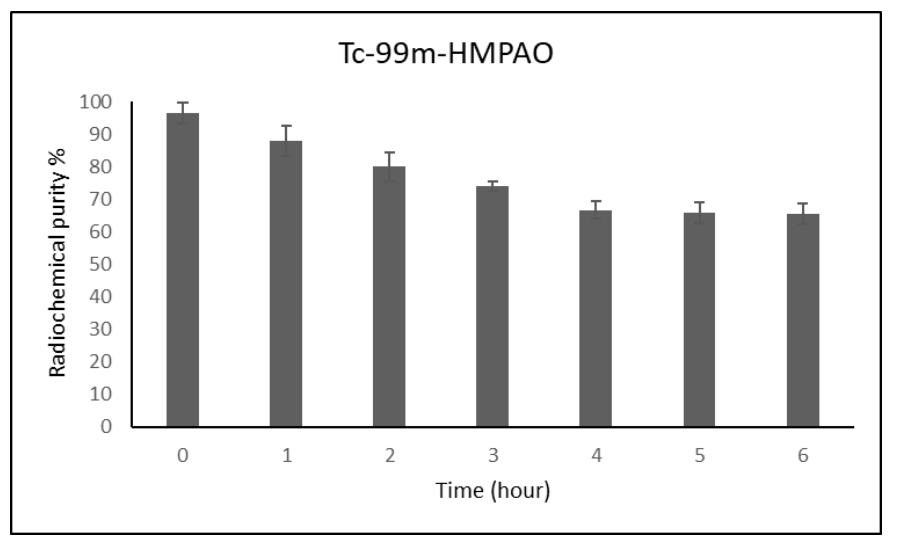

Figure 1. Radiochemical purity of [99mTc]Tc-HMPAO at room temperature.

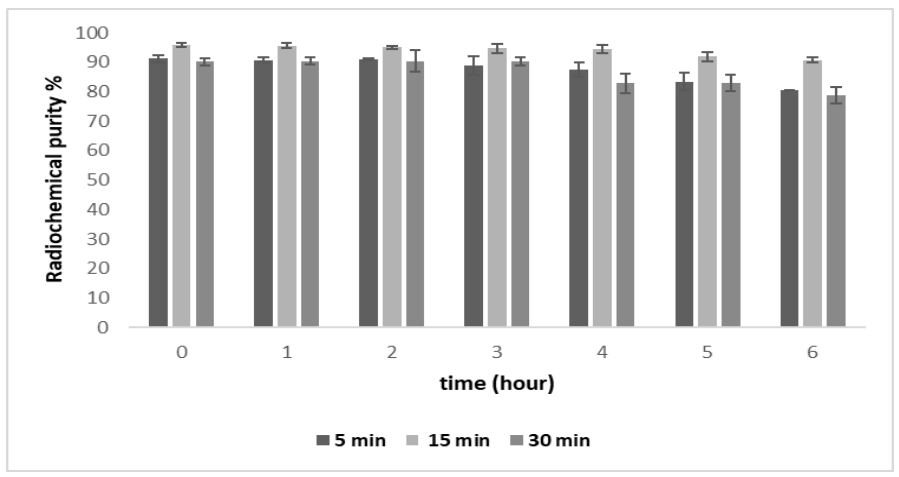

Figure 2. Effect of incubation time on radiochemical purity of [ ${ }^{99 \mathrm{~m} T c] T c-H M P A O-L P N}$ with $3.7 \mathrm{MBq}$.

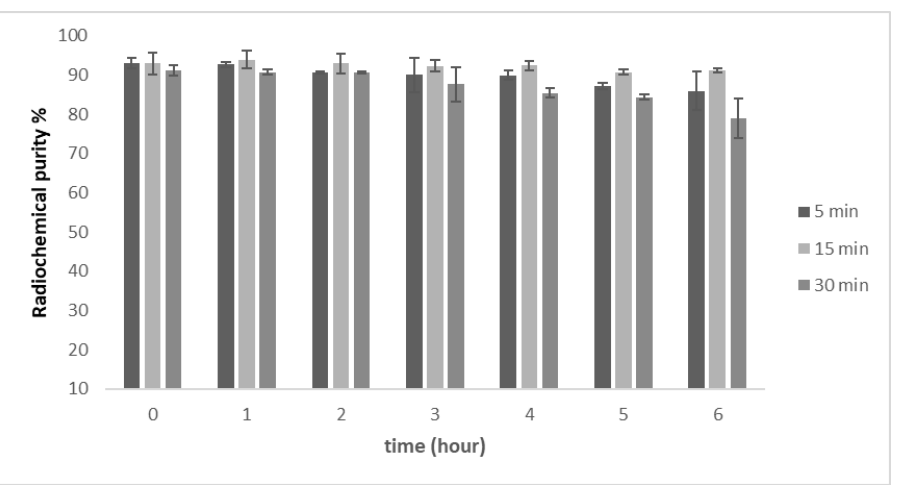

Figure 3. Effect of incubation time on radiochemical purity of [ ${ }^{99 \mathrm{mT}} \mathrm{Tc}$ ]Tc-HMPAO-LPN with 7.4 MBq.

The effect of radiation dose on radiochemical purity was examined at two different amounts (3.7 and 7.4 MBq). The radiochemical purity of [99mTc]Tc-HMPAO-LPN was found to be greater than $90 \%$ at 3.7 and 7.4 MBq of radiation doses with $15 \mathrm{~min}$ of incubation time. Our results demonstrate that while keeping other reaction conditions constant and varying the amount of radiation dose 3.7 and 7.4 MBq, radiochemical purity was not changed (Figure 4) and further studies were performed with these doses. 


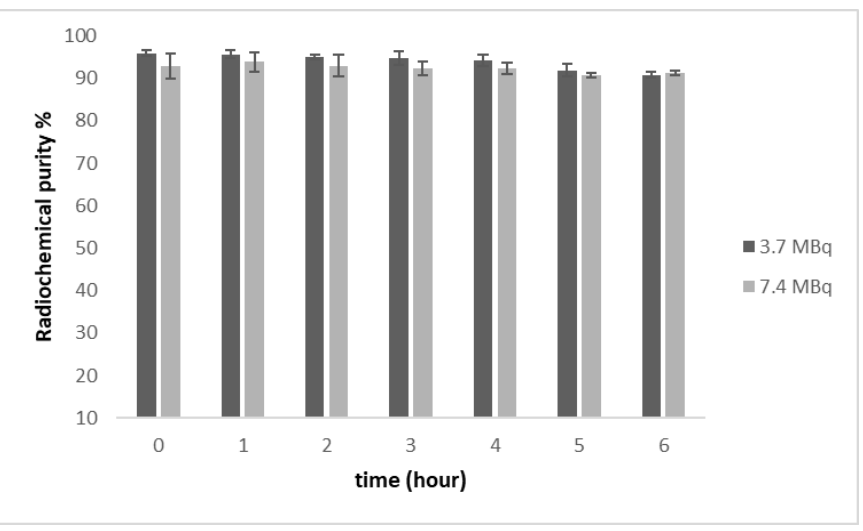

Figure 4. Effect of radiation dose on radiochemical purity of [99mTc]Tc-HMPAO-LPN.

\subsection{In vitro stability}

The radiochemical purity (\%) versus time of [99m Tc]Tc-HMPAO in saline and cell medium was shown in Figure 5. While, radiochemical purity of [ ${ }^{99 \mathrm{~m} T c] T c-H M P A O}$ was found to be $62.16 \pm 2.22 \%$ at cell medium, the radiochemical purity of [99mTc]Tc-HMPAO was found to be $62.63 \pm 4.09 \%$ at saline for $6 \mathrm{~h}$ (Figure 5).

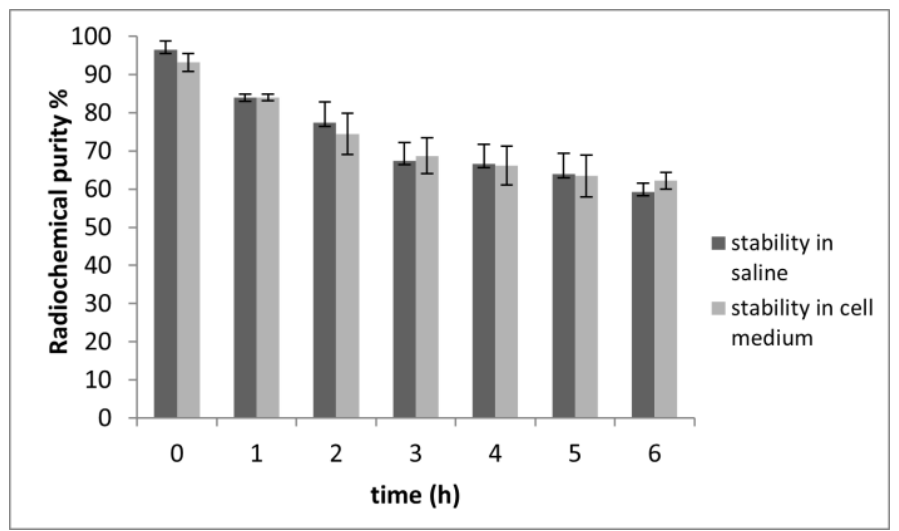

Figure 5. In vitro stability of [99mTc]Tc-HMPAO in saline and cell medium.

The stability of [99m Tc]Tc-HMPAO-LPN was evaluated in different media (saline and cell medium). The

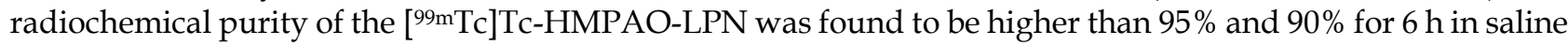
and cell medium, respectively at room temperature $(\mathrm{p}>0.05)$ (Figure 6).

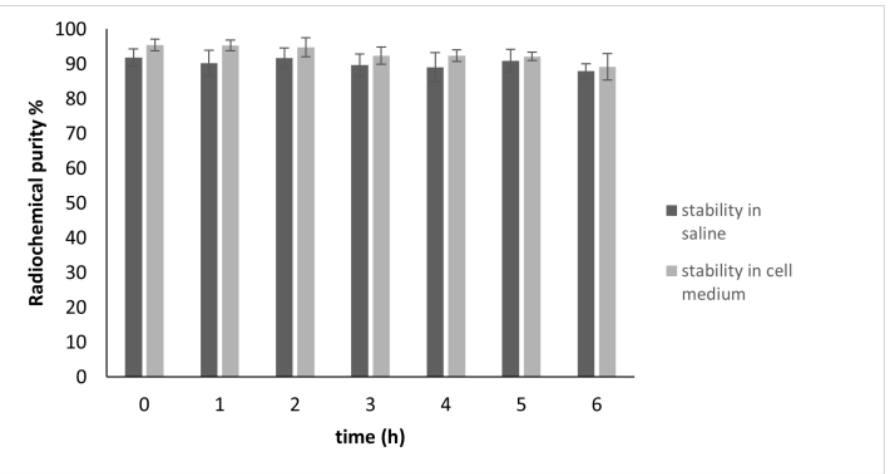

Figure 6. In vitro stability of [99mTc]Tc-HMPAO-LPN in saline and cell medium.

\subsection{Cell binding studies with [99m Tc] $\mathrm{NaTcO}_{4}^{-},\left[{ }^{99 \mathrm{mTc}} \mathrm{Tc}-\mathrm{HMPAO}\right.$ and $\left[{ }^{99 \mathrm{~m} T c] T c-H M P A O-L P N}\right.$}

The cell binding experiments were performed according to the literature methods [16,17]. MCF-7, PCS440-010 and CRL-10742 cells were used. The binding percentage of [ ${ }^{99 \mathrm{~m} T c] \mathrm{NaTcO}_{4}-}$, [99mTc]Tc-HMPAO and [99mTc]Tc-HMPAO-LPN with different doses (3.7 and 7.4 MBq) are shown in Table 10. After the administration of [ ${ }^{99 \mathrm{mTc}}$ ]Tc-HMPAO with $3.7 \mathrm{MBq}$, the cell binding percentage was found to be between $40.83 \pm 4.41 \%$ and 
$69.85 \pm 3.85 \%$ for all cells at 60 and $120 \mathrm{~min}$. On the other hand, after the administration of [99m Tc]Tc-HMPAO with $7.4 \mathrm{MBq}$, the cell binding percentages were found to be between $51.65 \pm 0.22 \%$ and $75 \pm 3.48 \%$ for all cells. While $38.29 \pm 1.05 \%$ and $48.67 \pm 1.37 \%$ of cell binding values were obtained for $3.7 \mathrm{MBq}$ of [99mTc] $\mathrm{NaTcO}_{4}$, $44.42 \pm 3.26 \%$ and $69.69 \pm 1.14 \%$ of cell binding percentage were obtained for $7.4 \mathrm{MBq}$ of [99mTc] $\mathrm{NaTcO}_{4}$. Furthermore, it was observed that the cell binding ratio of [99m Tc]Tc-HMPAO-LPN changed in range of 43.01 $\pm 2.22 \%-74.05 \pm 4.96 \%$ and $54.98 \pm 5.78-77.60 \pm 5.55$ for 3.7 and $7.4 \mathrm{MBq}$ doses, respectively.

Table 10. The cell binding ratio $(\%)$ of $\left[{ }^{99} \mathrm{mTc}\right] \mathrm{NaTcO}_{4}{ }^{-},[99 \mathrm{mTc}] \mathrm{Tc}-\mathrm{HMPAO}$ and [99mTc]Tc-HMPAO-LPN at different doses (Mean $\pm S D, n=3$ ).

\begin{tabular}{|c|c|c|c|c|c|c|}
\hline \multicolumn{7}{|c|}{ MCF-7 cells } \\
\hline & {$\left[{ }^{99 \mathrm{~m}} \mathrm{Tc}\right] \mathrm{NaTcO}_{4}^{-}$} & $\begin{array}{c}3.7 \mathrm{MBq} \\
{\left[{ }^{99 \mathrm{~m}} \mathrm{Tc}\right] \mathrm{Tc}-} \\
\text { HMPAO }\end{array}$ & $\begin{array}{c}{\left[{ }^{[99 \mathrm{~m}} \mathrm{Tc}\right] \mathrm{Tc}-} \\
\text { HMPAO-LPN }\end{array}$ & {$\left[{ }^{99 \mathrm{~m}} \mathrm{Tc}\right] \mathrm{NaTcO}_{4}^{-}$} & $\begin{array}{l}7.4 \mathrm{MBq} \\
{\left[{ }^{99 \mathrm{~m} T \mathrm{Tc}] \mathrm{Tc}-}\right.} \\
\text { HMPAO }\end{array}$ & $\begin{array}{c}\left.{ }^{[99 \mathrm{~m}} \mathrm{Tc}\right] \mathrm{Tc}- \\
\text { HMPAO-LPN }\end{array}$ \\
\hline $\begin{array}{l}60 \\
\min \end{array}$ & $45.02 \pm 1.91$ & $\begin{array}{l}57.19 \pm \\
8.74\end{array}$ & $61.81 \pm 2.36$ & $55.62 \pm 1.31$ & $60.89 \pm 1.02$ & $63.09 \pm 4.49$ \\
\hline $\begin{array}{l}120 \\
\min \end{array}$ & $48.67 \pm 1.37$ & $\begin{array}{c}56.46 \pm \\
7.83 \\
\end{array}$ & $62.58 \pm 0.11$ & $69.69 \pm 1.14$ & $61.23 \pm 3.48$ & $65.08 \pm 5.27$ \\
\hline \multicolumn{7}{|c|}{ CRL-10742 cells } \\
\hline & {$\left[{ }^{99 \mathrm{~m}} \mathrm{Tc}\right] \mathrm{NaTcO}_{4^{-}}$} & $\begin{array}{c}3.7 \mathrm{MBq} \\
{\left[{ }^{99 \mathrm{~m} T c] T c-}\right.} \\
\text { HMPAO }\end{array}$ & $\begin{array}{c}{\left[{ }^{99 \mathrm{~m} T c] T c-}\right.} \\
\text { HMPAO-LPN }\end{array}$ & {$\left[{ }^{99 \mathrm{mTc}}\right] \mathrm{NaTcO}_{4}^{-}$} & $\begin{array}{r}7.4 \mathrm{MBq} \\
\text { [99m Tc]Tc- } \\
\text { HMPAO }\end{array}$ & $\begin{array}{c}{\left[{ }^{99 \mathrm{~m} T c] T c-}\right.} \\
\text { HMPAO-LPN } \\
\end{array}$ \\
\hline $\begin{array}{l}60 \\
\min \end{array}$ & $48.52 \pm 6.84$ & $\begin{array}{c}57.19 \pm \\
8.74\end{array}$ & $69.13 \pm 4.41$ & $50.15 \pm 8.28$ & $69.74 \pm 6.44$ & $74.88 \pm 2.24$ \\
\hline $\begin{array}{l}120 \\
\min \end{array}$ & $56.28 \pm 1.26$ & $\begin{array}{c}69.95 \pm \\
3.85\end{array}$ & $74.05 \pm 4.96$ & $62.46 \pm 1.12$ & $73.58 \pm 2.25$ & $77.60 \pm 5.55$ \\
\hline \multicolumn{7}{|c|}{ PCS-440-010 cells } \\
\hline & {$\left[{ }^{99 \mathrm{~m}} \mathrm{Tc}\right] \mathrm{NaTcO}_{4}^{-}$} & $\begin{array}{c}3.7 \mathrm{MBq} \\
{\left[{ }^{99 \mathrm{~m} T c] T c-}\right.} \\
\text { HMPAO }\end{array}$ & $\begin{array}{c}{[99 \mathrm{mTc}] \mathrm{Tc}-} \\
\text { HMPAO-LPN }\end{array}$ & {$\left[{ }^{99 \mathrm{~m}} \mathrm{Tc}\right] \mathrm{NaTcO}_{4}^{-}$} & $\begin{array}{r}7.4 \mathrm{MBq} \\
{[99 \mathrm{~m} \mathrm{Tc}] \mathrm{Tc}-} \\
\text { HMPAO }\end{array}$ & $\begin{array}{c}{\left[{ }^{99 \mathrm{~m} T c] T c-}\right.} \\
\text { HMPAO-LPN }\end{array}$ \\
\hline $\begin{array}{l}60 \\
\min \end{array}$ & $38.29 \pm 1.05$ & $\begin{array}{c}40.83 \pm \\
4.41\end{array}$ & $43.01 \pm 2.22$ & $41.26 \pm 1.09$ & $51.65 \pm 0.22$ & $54.98 \pm 5.78$ \\
\hline $\begin{array}{l}120 \\
\min \end{array}$ & $42.17 \pm 9.84$ & $\begin{array}{l}53.99 \pm \\
1.48\end{array}$ & $46.75 \pm 9.81$ & $44.42 \pm 3.26$ & $55.72 \pm 2.56$ & $56.62 \pm 3.44$ \\
\hline
\end{tabular}

Evaluation of the results revealed that the highest binding ratio was observed with [99m Tc]Tc-HMPAO -LPN on CRL-10742 cell line and the lowest was on PCS-440-010 cell line with [99m Tc] $\mathrm{NaTcO}_{4}$. Also, the highest

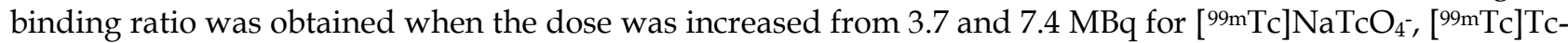
HMPAO and $\left[{ }^{99 \mathrm{~m} T c] T c-H M P A O-L P N ~}(\mathrm{p}<0.05)\right.$. Considering binding study results realized that there is

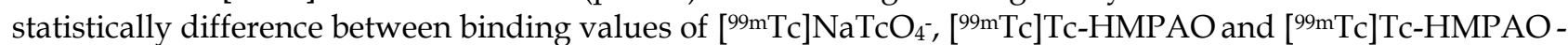
LPN $(\mathrm{p}<0.05)$.

\section{DISCUSSION}

Nanoparticles have important role as delivery systems of chemical compounds, imagining agents and others $[18,19]$. In this study, the new LPN formulations were developed by using lipid, surfactants, and aqueous phases. The polysorbate class of amphiphiles which can lead to best emulsification of the lipidic mixture and their combination with gelucire pellets cause by formation of LPN and providing stabilization of LPN. Hydrophilic solvents such as water, ethanol, propanol, butanol, pentanol, and hexanol have a critical role in the formation of LPN. They provide rapid distribution of lipid phase into the aqueous phase. Especially, ethanol and water have available properties such as low toxicity, facilitation of forming LPN for pharmaceutical administration with small particle size [13,14]. Hu et al. used a mixture of acetone:ethanol (1:1) as the aqueous phase in their studies [20,21]. Based on this information, water, ethanol, and acetone mixtures in various proportions as the aqueous phase were used in our previous work, and as a result of the characterization studies of the formulations, it concluded that the water:acetone:ethanol mixture works effectively as the aqueous phase [22]. So, herein, water and water:acetone:ethanol mixture were used as the aqueous phase.

The emulsification-sonication method has advantages such as ease of production process, short process time, homogeneous particle size, particle size reduction and obtaining stable formulation. Furthermore, it is available for the scale-up production [23]. In this study, stable LPNs were developed by these techniques. The 
desired particle size was achieved by $500 \mathrm{~W}$ and $20 \mathrm{kHz}$, between $10 \mathrm{~min}$ at $10000 \mathrm{rpm}$. Furthermore, when particle size, zeta potential/surface charge, polydispersity index and stability of LPN formulations were examined, emulsion and sonication techniques obtained optimum LPN (F-17) with suitable particle size, negative zeta potential, lower polydispersity index and stable formulation (Table 2-5). The zeta potential value shows the stability of nanoparticles and should be between $-30 \mathrm{mV}$ and $+30 \mathrm{mV}$. The LPN formulation has negatively charged particles with $-27.4 \pm 0.95 \mathrm{mV}$ according to measurements. Particle size is significant for targeting of colloidal systems. If colloidal systems have below $100 \mathrm{~nm}$ of size, they are able to enter capillaries in the tumor microenvironment and target to desired tissue and bigger than the pore size of healthy tissues, but smaller than the pores of cancer tissues. Thus, they are not possible for the drug to leave the blood stream and enter the tissue, but they can enter the cancer tissue through the pores, where they can accumulate [24]. In this study, particle size of LPN (F-17) is $93.5 \pm 1.17 \mathrm{~nm}$ and available for targeting with this value. PDI is dimensionless and scaled such that values smaller than 0.5 are rarely seen other than with highly monodisperse standards. PDI of F-17, ideal formulation, is found to be $0.35 \pm 0.04$.

[99m Tc]Tc is an ideal diagnostic radionuclide. In most labeled compounds, the center of molecules was coordinated with $\left[{ }^{99 \mathrm{~m}} \mathrm{Tc}\right] \mathrm{Tc}[25,26]$. Testing of radiochemical purity of radiopharmaceuticals is significant for quality control method in the daily routine of nuclear medicine departments. The radiolabeling procedures recommended by monographs in the European Pharmacopeia [25] for [99mTc]Tc-HMPAO.

In this study, radiochemical purity testing of [99mTc]Tc-HMPAO was modified. According to the European Pharmacopeia 8.5 instructions, while ITLC-SA is used as stationary phase ITLC-SG is used as stationary phase in this study. The lipophilic [99mTc]Tc-HMPAO complex was determined by using MEK (Rf= $0.8-1.0$ ), the secondary, free [ $\left.{ }^{99 \mathrm{~m} T c}\right] \mathrm{Tc}$ and [99mTc] Tc-HMPAO migrated with a unique peak ranging from Rf 0 to 0.4 in saline [26]. Herein, Rf values were found to be different from European Pharmacopei 8.5 instructions. The free [99mTc]Tc and [99mTc]Tc-HMPAO migrated with a unique peak ranging from Rf 0 to 0.1 in saline. It can be due to the changing of stationary phase $[27,28]$.

Radiolabeling of LPN was performed by using [ $\left.{ }^{99 \mathrm{mTc}} \mathrm{T}\right] \mathrm{Tc}-\mathrm{HMPAO}$. The stability of [99mTc]Tc-HMPAOLPN in saline and cell medium was examined. It was reported an efficient method for radiolabeling of liposome formulations using the GSH-HMPAO technique $[10,29]$. HMPAO is a $\left[{ }^{99 \mathrm{~m}} \mathrm{Tc}\right]$ chelator which has been clinically approved for brain imaging [30,31]. With this method, developed lipophilic [99mTc]Tc-HMPAO diffuses through the bilayer, and entraps within the aqueous phase of the liposome. This method showed that suitable in vivo stability is acceptable for labeling efficiency.

As shown in Figure 2 and Figure 3, the RP\% for 5-min incubation was below 85\%. To improve the RP values, the effect of various incubation times from 5 to $15 \mathrm{~min}$ and 15 to $30 \mathrm{~min}$ on $\mathrm{RP} \%$ was studied. The highest RP\% (above 90\%) was achieved following $15 \mathrm{~min}$ incubation. Various doses of [99mTc]Tc-HMPAO (3.7 an 7.4 MBq) were evaluated. The results (Figure 4) showed that the increase in doses did not affect the RP\% $(P>0.05)$ and a higher $\mathrm{RP} \%$ of $\sim 90 \%$ was obtained at these doses (Figure 4$)$. These results indicate the described method and optimum condition for radiolabeling is available for LPN. Furthermore, stability studies of the [99mTc]Tc-HMPAO and [99mTc]Tc-HMPAO-LPN in saline and cell medium (Figure 5 and Figure 6) showed that radiolabeled complexes were stable at least for $6 \mathrm{~h}$ at room temperature.

The present study investigates the effect of radiation dose and radiolabeled nanosystems on breast, prostate, and brain cancer cells with in vitro cell binding studies. [99m Tc] $\left.\mathrm{NaTcO}_{4}{ }^{-},{ }^{99 \mathrm{~m}} \mathrm{Tc}\right] \mathrm{Tc}-\mathrm{HMPAO}$ and [99mTc]Tc-HMPAO-LPN were used to examine the binding capacity of cells. Our findings (Table 10) are in agreement with the results of a study reported that the [99mTc]Tc-HMPAO had high binding in the brain cell because of its lipophilic structure.

[99mTc]Tc-HMPAO-LPN showed higher binding capacity than [99mTc]Tc-HMPAO (Table 10). The highest binding ratio was followed on CRL-10742 cell line with $7.4 \mathrm{MBq}$ of [99mTc]Tc-HMPAO-LPN and the lowest was on PCS-440-010 cell line with $3.7 \mathrm{MBq}$ of [99m $\mathrm{Tc}_{\mathrm{c}} \mathrm{NaTcO}_{4}{ }^{-}$. In previous studies, it was noticed that

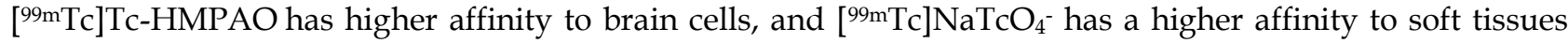
$[24,32]$. The obtained data from this study shows compliance with previous studies. In statistical analysis, One Way Anova was used to determine statistical significance. Differences at the $95 \%$ confidence level $(p<0.05)$ were considered significant. A significant difference was found for radiolabeled compounds at doses of 3.7 $\mathrm{MBq}$ and $7.4 \mathrm{MBq}$ for all cells. According to this, the radioactive dose affects cell binding capacity of radiolabeled compound.

The nanoparticles have commonly dissolved ingredients in body fluids, such as proteins, sugars, and lipids before their encounter with the cellular membranes. When they localized to desired area, the nanosystem content may be released outside or cells take up nanoparticles and unload content at the desired 
intracellular compartment. Generally, the transport of nanoparticles from the cell surface to the lysosomal vesicles occurs with a process known as endocytosis [33,34].

The cells are very sensitive and rapidly affected by ambient conditions and this may lead to differences in experimental results. Although the same studies are performed in different laboratories with the same conditions, the different results can be obtained between laboratories. Also, cell culture studies are thought to be guide in vivo studies and can be different from the results obtained in vivo studies. As can be seen in results, there are slight differences in magnitude that could be explained by the cell sensitivities such as different binding ratio of the radiolabeled compounds in the cells, cell numbers for each well and effect of medium conditions.

Several methods for cell viability have been described although only a few of them are in routine use, as many of these tests are time consuming. Herein, the MTT test was used to determine the number of viable cells which is based on the principle that living cells possess intact cell membranes that exclude certain dyes, whereas dead cells do not. The percentage of blue stained cell that have been damaged and dead during the feeding procedure should be below 15\% [15]. In this study, the percentage of dead cells is available for seeding process and binding capacity studies.

\section{CONCLUSION}

This work defines formulation, characterization and stability studies which resulted in the newly development of LPNs. All formulations were evaluated in terms of particle size, PDI, zeta potential, stability studies and the results prove that the availability of F-17 with below $100 \mathrm{~nm}$ of particle size, 0.5 of PDI and between $-30 \mathrm{mV}$ and $30 \mathrm{mV}$ of zeta potential. F-17 was successfully prepared by emulsion and sonication techniques and radiolabeled with [99m Tc]Tc-HMPAO. This radiolabeled complex showed high radiochemical purity and stable property in saline and cell medium. To demonstrate the in vitro cancer cell binding capacity of this compound, we realized cell binding studies with MCF-7, CRL-10742 and PCS-440-01 cells. [99mTc]TcHMPAO-LPN has higher cell binding capacity particularly in CRL-10742 when compared to [99mTc]Tc$\mathrm{HMPAO}$ and $[99 \mathrm{mTc}] \mathrm{NaTcO}_{4}-$. These results highlight the importance of thorough in vitro investigation of nanomedicines as well as long term in vivo toxicity monitoring of lipid-based nanoparticles. This is particularly important for LPNs developed for insensitive imaging modalities such as SPECT and gamma camera. Based on this work, we recommend that F-17 with good characterization, stability and non-toxic properties and also radiolabeled LPNs can be potential radiopharmaceutical complex for different cancer cell diagnosis. Furthermore, future studies with radiolabeled LPNs should carefully look into in depth in vitro cell culture studies, including cell binding assays with different cancer cell lines.

\section{MATERIALS AND METHODS}

\subsection{Materials}

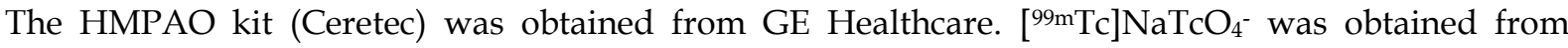
Department of Nuclear Medicine of Ege University. Cell culture reagents and supplies were obtained from Gibco Invitrogen (Grand Island, NY). The cells were obtained from American Type Culture Collection (ATCC).

\subsection{Preparation of LPN}

The new LPN formulations were developed by emulsion and sonication techniques. Several formulation assays were performed and gelucire derivatives, lecithin derivatives, tween 80 , span 80, lipoid derivatives were used to prepare LPNs. In general preparation, the lipid phase was melted at $75^{\circ} \mathrm{C}$ until a uniform and clear oil phase was obtained. Span 80 , Tween 80 , and lipoid derivatives were used as surfactants. The aqueous phase containing surfactants was heated at $75^{\circ} \mathrm{C}$ then added to the oil phase. The aqueous and oily phases were mixed under high-speed stirring $(10000 \mathrm{rpm})$ for $10 \mathrm{~min}$ using an Ultra-Turrax blender. After that, obtained pre-emulsion was sonicated at $500 \mathrm{~W}$ and $20 \mathrm{kHz}$ in changing $20 \mathrm{~s}$ cycles for 15 min by using Vibracell tip sonicator.

\subsection{Characterization of LPN}

\subsubsection{Particle size, polydispersity index and zeta potential analysis}

The formulations were evaluated with Malvern Zetasizer (Malvern Nano ZS 90) in particle size range of 3-1000 $\mathrm{nm}$ at room temperature with an angle of $173^{\circ}$ for aggregate formation particle size and 
polydispersity index. The zeta potential of formulations was measured at $40 \mathrm{~V} / \mathrm{cm}$ using a DTS 1060C zeta cuvette at $25^{\circ} \mathrm{C}, 78.5$ dielectric constants, $5 \mathrm{mS} / \mathrm{cm}$ conductivity. Measurements were performed in triplicates and results were exhibited as mean value \pm SD.

\subsection{Stability study}

The stability at $5 \pm 3^{\circ} \mathrm{C}, 25 \pm 5^{\circ} \mathrm{C}$ and $60 \pm 5 \%$ relative humidity $(\mathrm{RH}), 40 \pm 5^{\circ} \mathrm{C}$ and $75 \pm 5 \% \mathrm{RH}$ of the formulations were observed at certain time intervals for 6 months. The particle size, PDI, zeta potential and formulations appearance by visually were evaluated. All values were compared with statistically for the initial and time intervals values.

\subsection{Cell culture studies}

MCF-7, PCS-440-010 and CRL-10742 are an established cell line derived from breast, prostate, and brain tumors (ATCC). All cells were grown in Dulbecco Modified Eagle Medium (DMEM) supplemented with 10\% fetal bovine serum in a humidified atmosphere with $5 \% \mathrm{CO}_{2}$ at $37^{\circ} \mathrm{C}$. The cells were cultured in $25 \mathrm{~cm}^{2}$ flasks until they reached $80-90 \%$ confluence. After reaching $80-90 \%$ confluence, they were seeded at a density of $2 x$ $10^{6}$ cells/a well and allowed to multiply for $48-72 \mathrm{~h}$ for cell binding studies. The cells were prepared at a density of $1 \times 10^{5}$ cells/well for in vitro cytotoxicity studies.

\subsubsection{Cell viability studies}

The dye exclusion test was used to evaluate the cell viability for seeding procedure. $25 \mu \mathrm{L}$ of $0.4 \%$ trypan blue solution in water was added to $25 \mu \mathrm{L}$ of the cell suspensions and the solution was gently mixed. The blue mixtures have put a drop into a hemocytometer and place to phase-contrast microscope at 100 -fold magnification. The counting chamber for clumps and micro aggregates of cells, the number of blue-stained cells and non-blue stained cells were counted by visually.

\subsubsection{Cytotoxicity studies}

The cytotoxicity of developed LPNs (Formulation 7, 8, 10, 11, 14, 17, 18, 19, 20) was determined by the 3-(4,5-dimethyl-2-thiazolyl)-2,5-diphenyl-tetrazolium bromide (MTT) assay. MCF-7, PCS-440-010 and CRL10742 cells were plated in $0.1 \mathrm{~mL}$ of medium/well in 96-well plates (Costar Corning, Rochester, NY). They were incubated in the presence of LPNs in $0.1 \%$ DMSO for 24 and $48 \mathrm{~h}$ at $37^{\circ} \mathrm{C}$. The samples were removed and MTT in PBS was added. Viable cells were determined at $570 \mathrm{~nm}$. Measurements were performed and the amount required for $50 \%$ inhibition of viability $\left(\mathrm{IC}_{50}\right)$ was determined with GraphPad Prism.

\subsection{Preparation of $\left[{ }^{99 \mathrm{~m} T c] T c-H M P A O}\right.$}

The preparation of [99mTc]Tc-HMPAO has been modified according to European Pharmacopoeia [25]. The HMPAO kit is supplied as a pack of five vials for use in the preparation of [99m Tc]Tc-HMPAO solution as a nuclear medicine radiopharmaceutical. Each vial contains a pre-dispensed sterile, non-pyrogenic, lyophilized mixture of $0.5 \mathrm{mg} \mathrm{HMPAO}$, and $4.5 \mathrm{mg}$ sodium chloride, sealed under a nitrogen atmosphere. Approximately $1110 \mathrm{MBq}$ freshly eluted [99m $\mathrm{mc}^{9} \mathrm{NaTcO}_{4}-(2 \mathrm{~mL})$ was added to the vial of the HMPAO kit. The vial was stirred for a few seconds, filtered through a $0.22 \mu \mathrm{m}$ pore size filter, and incubated for $5 \mathrm{~min}$ at room temperature. After quality control procedure, the radioactivity dose of [ ${ }^{99 \mathrm{mTc}} \mathrm{Tc}$ Tc-HMPAO was set up 3.7 and 7.4 MBq. The radiochemical purity was analyzed by RTLC.

\subsection{Evaluation of radiochemical purity for $\left[{ }^{99 \mathrm{~m}} \mathrm{Tc}\right] \mathrm{Tc}-\mathrm{HMPAO}$}

The radiochemical purity of [99mTc]Tc-HMPAO was assessed by RTLC (Bioscan AR 2000) up to $6 \mathrm{~h}$. The method has been shown and modified in this study [25]. ITLC-SG was used as paper chromatography strip. The free $\left[{ }^{99 \mathrm{mTc}}\right] \mathrm{Tc}$ was determined by using saline as the mobile phase. $\mathrm{R} / \mathrm{H}\left[{ }^{99 \mathrm{~m} T \mathrm{Tc}}\right] \mathrm{Tc}$ was determined with

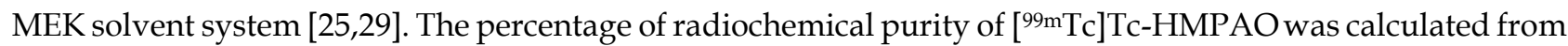
the following equation (Eq. 1) by subtracting from 100 the sum of measured impurities percentages:

Radiochemical Purity (RP) (\%) =100 - (Free 99mTc (\%) + R/H 99mTc (\%)) 


\subsection{Radiolabeling of LPN}

According to characterization and cytotoxicity results, formulation 17 (F-17) was selected. Preformed LPN (F-17) was labeled by [ ${ }^{99 \mathrm{~m} T c] T c-H M P A O} .0 .1 \mathrm{~mL}$ [99mTc]Tc-HMPAO added to $1 \mathrm{~mL}$ of F-17 for radiolabeling process. The effect of radiation dose and incubation time on radiolabeling procedure was investigated. Two different doses (3.7 and 7.4 MBq) and three different incubation times $(5,15,30-\mathrm{min})$ were evaluated for radiolabeling of LPN. 3.7 MBq of [99mTc]Tc-HMPAO was added to $1 \mathrm{~mL}$ of LPN formulation in a vial and mixed. The reaction mixture was gently stirred and incubated at room temperature for 5, 15 and 30min. After that, radiolabeled formulation was taken to the eppendorf and separated by centrifugation at $10000 \mathrm{~g}$ for a period of $10 \mathrm{~min}$ at $25^{\circ} \mathrm{C}$. At the end of the centrifugation, the supernatant was taken to another eppendorf. The radiochemical purity of formulation was assessed by using a gamma counter and calculated using Eq. 2:

$\mathrm{RP}(\%)=[$ Radioactivity of LPN / (Radioactivity of LPN + Radioactivity of supernatant) $] \times 100$

The same radiolabeling procedure was carried out 7.4 MBq of [99m Tc]Tc-HMPAO.

\subsection{In vitro stability of $\left[{ }^{99 \mathrm{~m}} \mathrm{Tc}\right] \mathrm{Tc}-\mathrm{HMPAO}$ and $\left[{ }^{99 \mathrm{~m}} \mathrm{Tc}\right] \mathrm{Tc}-\mathrm{HMPAO}-\mathrm{LPN}$}

In vitro stability of $\left[{ }^{99 \mathrm{mTc}} \mathrm{Tc}\right.$ Tc-HMPAO and [99mTc]Tc-HMPAO-LPN was performed at room temperature. $200 \mu \mathrm{L}$ [99m Tc] Tc-HMPAO and $\left[{ }^{99 \mathrm{~m} T c] T c-H M P A O-L P N}\right.$ incubated in $800 \mu \mathrm{L}$ saline and cell

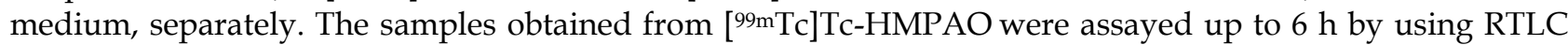
that was described above in "Evaluation of Radiochemical Purity" part. The samples obtained from [99mTc]TcHMPAO-LPN were analyzed to $6 \mathrm{~h}$ by using a gamma counter that was described in "Radiolabeling of LPN" part.

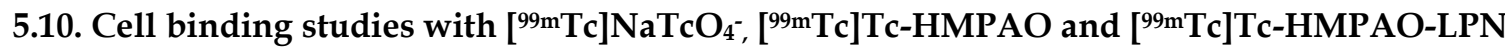

The cell binding studies were performed with MCF-7, PCS-440-010 and CRL-10742 to investigate the dose effect and binding capacity of formulations. The cells were incubated with 3.7 and $7.4 \mathrm{MBq}$ of [99mTc]TcHMPAO, [ ${ }^{99 \mathrm{~m} T c}$ ] $\mathrm{NaTcO}_{4}{ }^{-}$and [ ${ }^{99 \mathrm{~m}} \mathrm{Tc}$ ] Tc-HMPAO-LPN (F-17) for 60 and $120-\mathrm{min}$ at $37^{\circ} \mathrm{C}$, respectively. The cell culture medium was collected at 60 and 120-min. After removal of the cell culture medium, cells were trypsinized with $0.5 \mathrm{~mL}$ of trypsin to remove and cells were consecutively washed with $1 \mathrm{~mL}$ of cell medium and $1 \mathrm{~mL}$ of PBS to remove loosely bound surface radioactivity. The radioactivities, which in the tubes containing sediment cells and, in the tubes, containing culture medium were both counted by a gamma counter (Sesa Uniscaller). The cell binding ratio of cells was calculated from the following equation (Eq. 3) by dividing the radioactivity of cells to the total radioactivity (radioactivity of cells plus radioactivity of cell medium).

Radioactivity of Cells (\%) $=100 \times$ (Radioactivity of Cells / Total radioactivity)

\subsection{Statistical analysis}

The means and standard deviations of results were calculated on Microsoft Excel. Statistical analysis was performed by using Oneway Anova program. Differences at the $95 \%$ confidence level $(p<0.05)$ were considered significant. Experiments were performed in triplicate. Results are reported as mean \pm SD.

Acknowledgements: The authors would like to acknowledge the support of Ege University, Nuclear Medicine

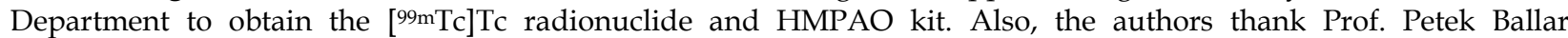
KırmıziBayrak from Ege University, Faculty of Pharmacy, Department of Biochemistry to support cell culture studies.

Author contributions: Concept - E.A-G., M.E., E.Ö., D.İ-Ö.; Design - E.A-G., M.E., E-S.D., D.İ-Ö.; Supervision - E.A-G., M.E., D.İ-Ö.; Resources - E.A-G., M.E., E.Ö., E-S.D., D.İ-Ö; Materials - E.A-G., M.E., E.Ö., E-S.D., D.İ-Ö; Data Collection and/or Processing - E.A-G., M.E., E.Ö., E-S.D.; Analysis and/or Interpretation - E.A-G., M.E., E.Ö., E-S.D.; Literature Search - E.A-G., M.E., E-S.D.; Writing - E.A-G., M.E., E-S.D.; Critical Reviews - E.A-G., M.E., E.Ö., E-S.D., D.İÖ.

Conflict of interest statement: The authors declared no conflict of interest. 


\section{REFERENCES}

[1] Ekinci M, İlem-Özdemir D. Current approaches in nanomedicine. Arch Nano Op Acc J. 2020; 2(3): 183-184. [CrossRef]

[2] Öztürk AA, Kiyan HT. Treatment of oxidative stress-induced pain and inflammation with dexketoprofen trometamol loaded different molecular weight chitosan nanoparticles: Formulation, characterization and anti-inflammatory activity by using in vivo HET-CAM assay. Microvasc Res. 2020; 128: 103961. [CrossRef]

[3] Merisko-Liversidge EM, Liversidge GG. Drug nanoparticles: Formulating poorly water-soluble compounds. Toxicol Pathol. 2008; 36(1): 43-48. [CrossRef]

[4] Krishnaiah Y. Pharmaceutical technologies for enhancing oral bioavailability of poorly soluble drugs. J Bioequiv Availab. 2010; 2(2): 28-36. [CrossRef]

[5] Öztürk AA, Namlı İ, Aygül A. Cefaclor monohydrate-loaded colon-targeted nanoparticles for use in COVID-19 dependent coinfections and intestinal symptoms: Formulation, characterization, release kinetics, and antimicrobial activity. Assay Drug Dev Technol. 2021; 19(3): 156-175. [CrossRef]

[6] Akbaba H, Karagöz U, Selamet Y, Kantarc1 AG. Synthesis and characterization of cationic lipid coated magnetic nanoparticles using multiple emulsions as microreactors. J Magn Magn Mater. 2017; 426; 518-524. [CrossRef]

[7] İlem-Özdemir D, Gündoğdu E, Ekinci M, Aşıkoğlu M. Nanoparticles: From diagnosis to therapy. Int J Med Nano Res. 2016; 3: 015. [CrossRef]

[8] Lim SB, Banerjee A, Önyüksel H. Improvement of drug safety by the use of lipid-based nanocarriers. J Control Release. 2012; 163(1): 34-45. [CrossRef]

[9] Ekinci M, İlem-Özdemir D. Radyofarmasötikler ve teranostikler. J Lit Pharm Sci. 2021; 10(1): 119-132. [CrossRef]

[10] Phillips WT, Rudolph AS, Goins B, Timmons JH, Klipper R, Blumhardt R. A simple method for producing a technetium-99m-labeled liposome which is stable in vivo. Int J Rad Appl Instrum B. 1992; 19(5): 539-547. [CrossRef]

[11] Öztürk AA, Yenilmez E, Arslan R, Şenel B, Yazan Y. Dexketoprofen trometamol loaded solid lipid nanoparticles (SLNs): Formulation, in vitro and in vivo evaluation. J Res Pharm. 2020; 24(1): 82-99. [CrossRef]

[12] Ekinci M. Master Thesis. Development of Tc-99m labeled drug delivery systems for diagnosis of breast cancer. Department of Radiopharmacy, Institute of Health Science, Ege University, Bornova, Izmir, Turkey, 2015.

[13] Negi LM, Jaggi M, Talegaonkar S. Development of protocol for screening the formulation components and the assessment of common quality problems of nano-structured lipid carriers. Int J Pharm. 2014; 461(1-2): 403-410. [CrossRef]

[14] Schubert S, Delaney JT, Schubert US. Nanoprecipitation and nanoformulation of polymers: From history to powerful possibilities beyond poly(lactic acid). Soft Matter. 2011; 7(5): 1581-1588. [CrossRef]

[15] Strober W. Trypan blue exclusion test of cell viability. Curr Protoc Immunol. 2015; 111: A3.B.1-A3.B.3. [CrossRef]

[16] Ekinci M, İlem-Özdemir D, Gündoğdu E, Aşıkoğlu M. Methotrexate loaded chitosan nanoparticles: Preparation, radiolabeling and in vitro evaluation for breast cancer diagnosis. J Drug Deliv Sci Technol. 2015; 30(A): $107-113$. [CrossRef]

[17] İlem-Özdemir D, Ekinci M, Gündoğdu E, Aşıkoğlu M. Estimating binding capability of radiopharmaceuticals by cell culture studies. Int J Med Nano Res. 2016; 3: 014. [CrossRef]

[18] Akbaba H, Erel-Akbaba G, Kotmakçı M, Başpınar Y. Enhanced cellular uptake and gene silencing activity of survivinsiRNA via ultrasound-mediated nanobubbles in lung cancer cells. Pharm Res. 2020; 37: 165. [CrossRef]

[19] Ekinci M, İlem-Özdemir D. Nanoteranostikler. Ankara Ecz Fak Derg. 2021; 45(1): 131-155. [CrossRef]

[20] Hu FQ, Jiang SP, Du YZ, Yuan H, Ye YQ, Zeng S. Preparation and characterization of stearic acid nanostructured lipid carriers by solvent diffusion method in an aqueous system. Colloids Surf B Biointerfaces. 2005; 45(3-4): 167173. [CrossRef]

[21] Hu FQ, Jiang SP, Du YZ, Yuan H, Ye YQ, Zeng S. Preparation and characteristics of monostearin nanostructured lipid carriers. Int J Pharm. 2006; 314(1): 83-89. [CrossRef]

[22] Gundogdu EA, Demir ES, Ekinci M, Ozgenc E, Ilem Ozdemir D, Senyigit Z, Asikoglu M. The effect of radiolabeled nanostructured lipid carrier systems containing imatinib mesylate on NIH-3T3 and CRL-1739 cells. Drug Deliv. 2020; 27(1): 1695-1703. [CrossRef]

[23] Hu C, Qian A, Wang Q, Xu F, He Y, Xu J. Industrialization of lipid nanoparticles: From laboratory-scale to large-scale production line. Eur J Pharm Biopharm. 2016; 109: 206-213. [CrossRef] 
[24] Bahari LA, Hamishehkar H. The impact of variables on particle size of solid lipid nanoparticles and nanostructured lipid carriers; a comparative literature review. Adv Pharm Bull. 2016; 6(2): 143-148. [CrossRef]

[25] Technetium $(99 \mathrm{mTc})$ exametazime injection, European pharmacopoeia online 8.5. Council of Europe. http://online6.edqm.eu/ep805/ (accessed on 8 Sep 2019).

[26] Huang H, Mei L, Chu T. Synthesis, radiolabeling and biological evaluation of propylene amine oxime complexes containing nitrotriazoles as hypoxia markers. Molecules. 2012; 17(6): 6808-6820. [CrossRef]

[27] Kim EE. Radiopharmaceuticals in nuclear pharmacy and nuclear medicine. J Nucl Med. 2013; 54(2): 324-325. [CrossRef]

[28] Amin AM, El-Azony KM, Ibrahim IT. Application of ${ }^{99} \mathrm{Mo} / 99 \mathrm{mTc}$ alumina generator in the labeling of metoprolol for diagnostic purposes. J Label Compound Radiopharm. 2009; 52(11): 467-472. [CrossRef]

[29] Suzuki C, Kosugi M, Magata. Noninvasive quantitation of rat cerebral blood flow using 99mTc-HMPAO assessment of input function with dynamic chest planar imaging. Eur J Nucl Med Mol I. 2018; 8: 21-25. [CrossRef]

[30] Bonte FJ, Hynan L, Harris TS, White CL. Tc-99m HMPAO brain blood flow imaging in the dementias with histopathologic correlation in 73 patients. Int J Mol Imaging. 2011; 409: 1-3. [CrossRef]

[31] Blankenberg FG, Kinsman SL, Cohen BH, Goris ML, Spicer KM, Perlman SL. Brain uptake of Tc99m-HMPAO correlates with clinical response to the novel redox modulating agent EPI-743 in patients with mitochondrial disease. Mol Genet Metab. 2012; 107(4): 690-699. [CrossRef]

[32] Apar Kaya G, Bekis R, Yılmaz O, Ertay T, Durak H. Tc-99m HMPAO uptake in soft tissue infection. Turkish J of Nucl Med. 2005; 14: 130-132.

[33] Treuel L, Jiang X, Nienhaus GU. New views on cellular uptake and trafficking of manufactured nanoparticles. J Royal Society Interface. 2013; 10(82): 20120939. [CrossRef]

[34] Park S, Lee SJ, Chung H, Her S, Choi Y, Kim K, Choi K, Kwon IC. Cellular uptake pathway and drug release characteristics of drug- encapsulated glycol chitosan nanoparticles in live cells. Microscopy ResTechnique. 2010; 73(9): 857-865. [CrossRef]

This is an open access article which is publicly available on our journal's website under Institutional Repository at http://dspace.marmara.edu.tr. 